\title{
The Role of Social Media for Instructional Purposes
}

\author{
Nithiwadee Kosarassawadee, Aungkana Sukweses, and Chaiwat Tantarangsee
}

\begin{abstract}
The purposes of this study are to find out functions achieved in social media-based activities for instructional purposes, and the faculty members' opinions towards the use of social media for such purposes. Samples include 31 faculty members, Faculty of Humanities and Social Sciences, Suan Sunandha Rajabhat University (SSRU), Bangkok, Thailand. A questionnaire is used to collect data. The study discloses 3 functions achieved in social media-based activities for instructional purposes with average time consumption of more than 5 times a week, namely retrieving contents for classroom instruction from websites and YouTube followed by presenting contents from websites and YouTube in classroom instruction, and communicating with students through Line. Moreover, the opinions of the samples towards the use of social media for instructional purposes indicate their perceived value of the usefulness of such media. The opinions with highest mean scores include delivering information, and contents to students followed by satisfying students' need to be tech-savvy, and facilitating communication and collaboration among teachers and students. It can be concluded that the faculty members perceive the technology usefulness of social media and make use of it to develop information retrieval skills and online relationships.
\end{abstract}

Index Terms-Social media-based activities, social media for instructional purposes, tech-savvy, and the online community of inquiry.

\section{INTRODUCTION}

Due to the fast growing Information Communication Technology, English is a vital tool for communication among people around the world. That is because the Internet or World Wide Web enables an important event happening in a part of the world to be simultaneously and clearly broadcast to people in other parts of the world with pictures, texts, and video clip, etc. [1]. People with different races who speak different languages can consume the same piece of information or news, and share it to other internet users or netizens, and of course the core language used on the internet or websites is English language [2]. That's why English is regarded as "World Language”, or "Global Language” [3]. The impact of English as World Language on Thai students learning English language is that channel of the communication is not between Thais and native speakers of English, but between Thais and other non-native speakers of English. Moreover, the communication channel does not lie on face to face communication, but it mostly lies on reading contents from

Manuscript received December 20, 2017; revised February 7, 2018. This work was supported in part by Suan Sunandha Rajabhat University Personal Development Fund.

The authors are with English Language Program, Faculty of Humanities and Social Sciences, Suan Sunandha Rajabhat University, Thailand (e-mail: nithiwaseek@yahoo.com, aungko_su@ssru.ac.th, ceewattantar@yahoo.com). various online sources including messages from social media tools and striking key boards on mobile phones for communication and fun in daily life [4]. This leads to the term "Texting Generation" referring to young people who excessively love texting messages to one another anywhere and anytime.

Since time passes, the need of internet users has been satisfied more and more by the development of web technology from 1.0 - webs presenting only texts to 2.0 or web application or programs enabling each user to be able not only to retrieve information in the form of texts, pictures, and video clips but also to connect to one another on web pages [5]. And this kind of online communication technology has become 'social media'. 'Social Media' lies on more than 1 billion users sharing their personal data on this online communication technology which is, therefore, called 'Social Media'. The convenience and charm of the social media capture the attention, and consume much longer time of more and more internet users. The most popular network worldwide as of January 2017 ranked by number of active accounts is market leader Facebook - the first social network to surpass 1 billion registered accounts [6]. Based on the survey by The Office of Electronic Business Development, Bangkok, Thailand, it is found that Thai active social media users as a percentage of total population is $56 \%$, and Generation Y social media users or those who are 19-29 years old is the largest group [7]. Moreover, the top active social platform includes Facebook followed by Line, Facebook messengers, Google +, Instagram, Twitter, and etc. Average time spent with the Internet via PC or a Tablet is 4.45 hours a day, while via mobile phone is 3.35 hours a day. In addition, average daily use of social media via any device by Thai people is 2 hours 52 minutes a day [8].

Based on these findings, it can be concluded that most university students and faculty members spend some of their time on social media a day, and they use social media for personal purposes and enjoyment. However, the most common language used on the Internet including social media is English language. Ongoing monitoring by W3Techs showed that in March 2015, just over 55 percent of the most visited websites had English-language homepages [8]. The assumption is that students use some English while surfing the net and social network. Due to its perceived enjoyment and social influence, they probably learn or at least practice using English and together informally and independently on the net including social media outside the classroom [9]. However, in terms of teaching pedagogies and learning styles, application of social media in learning contexts has transformed increasingly teaching method, curriculum design, and some conception of learning strategies in any field of study [10]. That is to say teachers have moved from the application of 'talk \& chalk' to 'point \& click', and now the application of 
social media enables classroom instruction in any field of study in which learners' needs for relationship, and self-actualization can be satisfied. In addition, the usual teaching steps: 3Ps or Presentation, Practice and Production can be blended with the impact of social media by the consideration of 'post, share and like.'

Meanwhile, the development of Information Communication Technology and social media affect the teaching and learning in some aspects. In classroom contexts, some learning management systems allow learners to learn from a variety of multimedia with pictures, texts, sounds, YouTube, etc. both in class and outside class while teachers can make use of the new media to facilitate learning and teaching in more dynamic ways. Communication between teachers and students or students and students take place not only in classroom setting but also on web-blogs, Facebook, etc. The teaching methodologies have included "Task-based learning" and "Project-based learning" in course design. It is, therefore, common for teachers to assign students to engage with contents in the real world outside the class and bring into the class the authentic piece of the real life interests in the forms of reports or classroom presentation. In the meanwhile, students upon their own interest and the drive of being tech-savvy spend most of their time on social media. But by ignoring what students do with social media outside the classroom or refusing to engage with our students in social media, teachers will never truly understand their needs and never fully realize potential of social media as a learning tool. It is necessary now to study the role of using social media for instructional purposes. The purposes of this study are to identify 1) the functions achieved in social media-based activities for academic purposes, and 2) the faculty members' opinions towards the use of social media for such purposes.

\section{TheORETICAL BACKGROUND}

\section{A. Definition of Social Media}

The term 'social media' is frequently mentioned in various contexts with different meaning. Here are some definitions.

The term 'social media' can be divided into two parts; 'social' and 'media'. The word 'social' means 'interacting with the people by sharing information with them and receiving information from them', while 'media' in today context refers to 'the Internet.' When the two parts are combined, 'social media' is, therefore, referred to 'web-based communication tools that enable people to interact with each other by both sharing and communicating information' [11]. Additionally, another definition of 'social media' is 'social media-mediated technologies that allow the creating and sharing of information, ideas, career interests and other forms of expression via virtual communities and networks' [12]. Based on the above definitions the use of social media has changed people's communicative patterns over the last 10 years by enabling users "to create, distribute, share and manipulate different types of content, most of them publicly accessible" [13]. "Social Media” can be, therefore, defined as online media enabling users to interact with one another online through various web application allowing users to create, distribute, share and manipulate a variety of contents including texts, pictures, video, songs, etc. to other net-users, and these contents can be accessible publicly. Social media investigated in this study include Websites and YouTube, Facebook, Line, Facebook messengers, Google +, Twitter, Instragram, Blogs, Moodle.

\section{B. State-of-the-Art Social Media}

'Social Media' or 'Social Media Networking' has become more and more popular each year. New research reveals global social media use increased by 21 percent in 2016 [8].

The reasons why more and more people spend longer time each day on social media lie on its functions that fulfill users' needs and preference; perceived enjoyment and perceived usefulness.

Social media serves users' perceived enjoyment and social influence. In the case of Facebook - the top active social platform with 32\% of Internet users, there are functions that attract users to come to the site regularly, such as updating user's profile, posting user's photos and comments, joining groups of the same interest, and staying connected with others on Facebook messenger, etc. These interactive functions of Facebook can fulfill human's needs and compensate personal lacking, such as the need for self-actualization, self-esteem, relationship, and achievement as well as the need to be belonging [14].

In the case of the need for self-esteem, those who regularly updating their profiles, their photos, and timeline on Facebook may fulfil their needs to build their self-esteem.

These kinds of social media-based activities satisfy users' feelings of being happy with their own characters and abilities. In fact, without social media, creating someone's self-esteem requires lots more courage and time, while with social media, creating self-esteem seems to be easy and trendy. In the case of the need for self-actualization, relationship, and achievement, Facebook enables users to add friends, express affection through "Like" click with lovely and catchy stickers, and provide some praise, comfort, chat, etc., through comment. Once again, social media makes it easier for people to express their feeling and provide comments which are hard or uneasy to say face to face. This in-turn fulfils user's need for social relationship. However, these kinds of online communication can keep people together while there will be some cases of arguments and online bullying.

In addition, social media serves users' perceived usefulness. Due to the ease of use of social media which is designed with the concept of being 'user-friendly'. That is to say social media sites are so easy to navigate that they require very less knowledge of the Internet allowing more people to connect through them. Moreover, some popular sites - Facebook and Google+ are free. Contents with eye-catching and attractive photos and images, as well as real scene of immediate situation including accidents, theft, robbery, violence, crime and unexpected occurrence can be shared on social media for different purposes, such as for entertainment, knowledge 
exchange, educational purposes and law suit. Social media users serve as both content providers and content consumers. As content providers, these users will get immediate response in the forms of comment and like. As content consumers, large amount of contents in various topics can be explored and justified for their own preference. In Feedback, comments in the forms of like, comment and share are available for all users. All these are more reasons why social media is becoming more and more popular.

\section{Pedagogical Use of Social Media for Instructional Purposes}

Since one of the top social media platforms - Facebook firstly used in Harvard University a decade ago before extending to other colleges in US by Mark Zukerberg and his college friends, now it has been widely used by millions of people around the world in daily life, and in various careers especially in business and marketing [6]. Social media has been used in education and English language teaching for some time while $66 \%$ of all adults ages $16+$ have a profile or at least one social network site [8]. Since then universities and other education providers have responded by the increased use of social media market to showcase their courses and attract students. Moreover, social media has been common in universities providing distance learning education or e-learning. In this case, distance learning providers are required to manage their online courses to keep pace with any trends and technological advances which promote communication with students and enhance learning experiences.

A pedagogical model concerning good practice for the online classroom and online learning called 'Online Community of Inquiry' has been considered by faculty members and educators responsible for online instruction and blended online learning. Community of Inquiry is a model of learning online in which meaningful learning occurs best when teachers and students form a cohesive community of inquiry. The online community of inquiry is based on the three core elements; social presence, teaching presence, and cognitive presence [15]. The online technology supporting this model is video conferencing. In the past few years it is noted that higher-order learning occurring through the interaction of three core elements in this model could be delivered by video conferencing. However, at the dawn of Facebook, the online community of inquiry can be defined as a model that values collaborative learning through discussion and involves the interaction of three overlapping elements: teaching presence, social presence and cognitive presence [15].

Social presence is the ability of learners and teachers to project their personal characteristics into the online community of inquiry through presenting themselves as 'real people.' It is, therefore, teachers' job to encourage collaborations by providing a social networking site for communication within a trusted and friendly environment where students can express individual identities and establish social relationships. Additionally, teachers can regularly present themselves on this site, as well. In terms of the integration of social media in classroom instruction, social presence can be supported by social media platforms, such as Facebook and Facebook messengers together with social media-based activities.

Teaching presence is broadly characterized as the virtual 'visibility' of an instructor in an online learning environment [16]. Teaching presence, therefore, relates to the process of course design, facilitation, and direction throughout the learning experience to achieve desired learning outcome. Teachers can guide students through course materials, reinforcing key concepts, providing formative feedback and support for students through various social media platforms. Social media, then, helps faculty members in classroom, and course management both in class and outside class. That is to say teachers using social media as teaching-aids online as well as in classroom instruction.

Cognitive presence is the extent to which learners are able to construct and confirm meaning through sustained personal reflection and discourse [17]. In addition, cognitive presence can be defined as the extent to which participants in any particular configuration of an online community of inquiry are able to construct meaning through sustained communication [15]. In terms of using social media in classroom instruction, cognitive presence relates to how students move through the learning process inside and outside classroom - approaching problems, seeking out new knowledge, gaining new level of understanding, and sharing such understanding with learning community. In another context, cognitive presence refers to how students integrate key concepts from the classroom into their own worlds, explore related resources, and bring new knowledge and ideas into the learning process. This kind of process can be found in learning activities such as task-based learning, project-based learning, social media-based activities, etc.

Social media or social media networking has long been used in distance education and e-learning. Nowadays due to the fascinating social media, it can be integrated the use of social media or social networking sites in classroom instruction with the concept of the online community of inquiry which can assist and motivate learners to have fun and become autonomous and independent learners.

\section{Social Media for Instructional Purposes}

Application of social media for instructional purposes and

language learning has transformed pedagogy, curriculum design, the concept of teaching and learning, and even the research in this field [13]. Here are the functions achieved in social media-based activities for instructional purposes.

The functions of social media for instructional purposes can be divided into 3 groups based on core elements of the Online Community of Inquiry.

1) Due to the charm of Facebook, learners as well as teachers can fulfill their needs to present their identities and self-esteem by using creating, distributing, sharing and manipulating contents in the forms of texts, photos, video clips, etc. for educational purposes. At the same time, it's 
teachers' jobs to monitor and shape up the sites in case of online bullying and inappropriate contents. The example of a basic social media-based activity to promote social presence is to assign learners to create their profiles using the target language in their field of study, and ask other students to make comments. This activity allows students as content providers to use social media to create their identity and keep updating their time line while as content consumers to interact with others with good online manners to maintain good online relationship.

2) Social media can be used in class management, such as to present learning materials, lesson plans, class schedule, online practice, feedback, grade summary, etc. Moreover, it is widely used for communication between teachers and learners as well as among learners in the forms of web-board announcement, and online forum. In addition, online discussion board provides chances for students to express their ideas as well as to use the target language to achieve their desired communication goals [15]. This kind of purposes of using social media in class management supports online teaching presence leading to successful teaching and learning. It is, therefore, necessary for faculty members to make use of social media in class management and curriculum design [10].

Social media can, also, be used in formal classroom instruction. For example, due to the ease of use of the Internet in classroom setting in most educational institutions, variety of online sources in the forms of texts, pictures, and video clips can be accessed real time in class and used as warm up activities, leaning materials, exercises, and tests. Since most online sources, such as news articles, news programs, documentaries, TV programs, etc., are produced professionally, these sources can surely enrich the students' knowledge and experiences.

3) Social media can support students' cognitive presence.

As social media has become part of students' daily life, students spend long hours using social media for communication. However, using social media for instructional purposes can motivate them to learn by themselves, assist critical thinking, and create collaborations. For example, in social media-based activities requiring students to create a particular content in the form of project and/or oral presentation, social media can support these activities by its unique function allowing users to create content, share, and comment [18]. Moreover, in terms of learner's based activities, it is common and effective for students to retrieve various information or contents from websites and bring authentic and current sources in the forms of texts, pictures, graphs, charts, and video clips to class for learning and discussion [12]. Social media can, therefore, be valuable sources for classroom instruction with catchy and trendy selected teaching aids brought by teachers and students. Moreover, social media helps support students' engagement in learning and bridging authentic world outside class to classroom contexts. Additionally, in class it is teachers' job to let the students be aware of netiquette [19]. For example, students should be informed of copyrights, safety and danger in using social media, and proper roles of being content providers and consumers.

Social media-based activities become common in classroom instruction due to the fast growing Information Communication Technology, and the dawn of social media platforms. Blogs which is a self-published, web-based collection of writing and photos calls for regular updates, exchange of comments, and short posts. Blogs, therefore, offer a hugely exciting platform for learners to express themselves. Moreover, since posts on blogs are usually short, and new content is added regularly, blogs are attractive and exciting for classroom adaptation. For example, building a class blog where students can take turn writing posts on controlled topic while other students are required to add comment will enable students to develop thinking skills as well as communication skills. In addition, lessons based on blogs can be created with the purpose of language practice, language analysis, and reading comprehension [20].

YouTube with video sharing, commenting and viewing becomes popular among social media users all over the world.

Billions of visitors visit YouTube each day with over 6 billion hours of video watched each month, and 100 hours of video uploaded every minute [10]. This enables YouTube to be excellent database of multimedia content which promotes autonomous, and student-centered learning. YouTube can be excellent supplement tools for classroom instruction. For example, short clip can effectively and lively be used to introduce subject matter, illustrate a particular point, review important points taught, and close lessons. Moreover, in some advanced class, oral discussion on the content of a video on YouTube before or during class can motivate students to share their opinions and give comments.

Various social media platforms are ready to be used for instructional purposes so that knowledge and language available in real world can be brought into classroom setting actively, effectively, and enjoyably through medium of leaners' choice. This research is, therefore, aimed to study the role of social media for instructional purposes.

\section{RESEARCH DESIGN}

\section{A. Samples and Procedures}

Samples of this study are 31 faculty members in Faculty of Humanities and Social Sciences, Suan Sunandha Rajabhat University (SSRU), Bangkok, Thailand. Data is collected by using a 5-scale questionnaire which has been verified and tried out. Here are the details of the 5 rating scales.

TABLE I: DETAILS OF THE 5 RATING SCALE

\begin{tabular}{cl}
\hline \hline Level of Frequency & $\begin{array}{l}\text { Duration of time spent on social media-based } \\
\text { instruction }\end{array}$ \\
\hline 5 & $\begin{array}{l}\text { Highest level - more than } 5 \text { times a week } \\
4\end{array}$ \\
3 & High level - average 4-5 times a week \\
2 & Lodium level - average 3-4 times a week \\
1 & Lowest level - average 1-2 times a week \\
\hline \hline
\end{tabular}

Table I shows details of the 5 rating scales. The amount of 
time provided in the scales is in line with the research findings revealed in 'Global social media research summary 2017' [6].

The questionnaire includes 3 parts, namely 1) Background of respondents, 2) Functions achieved in social media-based activities, and 3) The faculty members' opinions towards the use of such social media. In part 2, 20 functions achieved in social media-based activities are included.

Data from the questionnaire is analyzed by SPSS program, and statistics employed include percentage, Mean, and Standard Deviation.

\section{B. Research Questions}

Based on the purposes of this study, which include to find out the functions achieved in social media-based activities for instructional purposes created by faculty members of Faculty of Humanities and Social Sciences, Suan Sunandha Rajabhat University, Bangkok, Thailand and their opinions towards the use of such social media, the research questions are as follows;

1) What functions can social media-based activities for instructional purposes serve? And to what extent is each function used?

2) What are the faculty members' opinions towards the use of social media for instructional purposes?

\section{Results And Discussion}

The research findings reveal 8 functions most frequently achieved in social media-based activities for instructional purposes created by faculty members of Faculty of Humanities and Social Sciences, Suan Sunandha Rajabhat University, and their attitudes towards the use of social medial for instructional purposes. The details of the findings are as follows;

\section{A. Functions Achieved in Social Media-Based Activities}

Table II shows 8 functions achieved in social media-based activities by faculty members of Faculty of Humanities and Social Sciences. 3 functions are achieved in high level with average time consumption of 4-5 times a week. The function with highest mean score includes retrieving contents for classroom instruction from websites and YouTube followed by presenting contents from websites and YouTube in classroom instruction and communicating with students through Line. Moreover, 5 functions achieved in moderate level with average time consumption of 3-4 times a week. These functions include assigning students to retrieve information from websites and YouTube to write reports, uploading PowerPoint presentation on Moodle, uploading contents for classroom instruction on Moodle, assigning learners to share contents and exercises related to the field of study on Moodle, and posting contents and photos related to the field of study on Facebook for knowledge exchanging and comments.

It can be noted that 5 out of 8 functions are achieved by the faculty members, while 2 functions are achieved by the students, and 1 function is to maintain online relationship between teachers and students. Function achieved by the faculty member includes retrieving contents for classroom instruction from websites and YouTube, presenting contents from websites and YouTube in classroom instruction, uploading PowerPoint presentation and contents for classroom instruction on Moodle, and posting contents and photos relating to the field of study on Facebook for knowledge exchanging and comments. However, functions achieved by the students includes retrieving information from websites and YouTube to write reports and sharing contents and exercises related to the field of study on Moodle. Moreover, one function achieved by both teachers and students is communicating with students through Line.

\begin{tabular}{|c|c|c|c|}
\hline No & Achieved Function & Means & S.D. \\
\hline 1 & $\begin{array}{l}\text { Retrieve contents for classroom instruction } \\
\text { from websites and YouTube }\end{array}$ & 4.13 & 1.17 \\
\hline 2 & $\begin{array}{l}\text { Present contents from websites and YouTube } \\
\text { in classroom instruction }\end{array}$ & 3.68 & 1.44 \\
\hline 3 & Communicating with students through Line & 3.55 & 1.58 \\
\hline 4 & $\begin{array}{l}\text { Assign learners to retrieve information from } \\
\text { websites and YouTube to write reports }\end{array}$ & 3.32 & 1.37 \\
\hline 5 & Upload PowerPoint presentation on Moodle & 2.74 & 1.54 \\
\hline 6 & $\begin{array}{l}\text { Upload contents for classroom instruction } \\
\text { on Moodle }\end{array}$ & 2.55 & 1.48 \\
\hline 7 & $\begin{array}{l}\text { Assign learners to share contents and exercises } \\
\text { related to the field of study on Moodle }\end{array}$ & 2.55 & 1.22 \\
\hline 8 & $\begin{array}{l}\text { Post contents and photos related to the field of } \\
\text { study on Facebook for knowledge exchanging } \\
\text { and comments }\end{array}$ & 2.54 & 1.32 \\
\hline
\end{tabular}

This leads to the point that faculty members have used social media not only in classroom management but also in classroom instruction. The faculty members themselves mostly use social media in course design, and course instruction. In addition, the faculty members designed social media-based activities for instructional purposes to allow the students to use social media to accomplish learning outcome. Teachers also make use of social media as teaching tools, and adopt the role as facilitators for learners to maintain online relationships leading to community building with interaction and collaboration academically.

TABLE III: OpINIONS TOWARDS THE USE OF SOCIAL MEDIA

\begin{tabular}{llcc}
\hline \hline No & List of Opinions & Means & S.D. \\
\hline 1 & $\begin{array}{l}\text { Transferring information and contents to } \\
\text { students }\end{array}$ & 4.32 & 1.17 \\
2 & Satisfying the students' need to be tech-savvy & 4.26 & 1.24 \\
& & & \\
3 & Brightening up classroom climate & 4.26 & 1.24 \\
4 & Maintaining online relationship & 4.13 & 1.25 \\
5 & Supporting communication & 4.10 & 1.35 \\
6 & Supporting teaching and learning management & 4.03 & 1.38 \\
7 & Supporting students' online collaborations & 4.00 & 1.29 \\
8 & Shaping up students' netiquette & 3.94 & 1.46 \\
& & & \\
\hline \hline
\end{tabular}

\section{B. Faculty Members' Opinions towards the Use of Social Media for Instructional Purposes}

Table III shows the faculty members' opinions towards the role of social media for instructional purposes. The lists of 
opinions in highest level include transferring information and contents to students followed by satisfying the needs of tech-savvy students to use social media for learning and brightening up the classroom climate. The lists of opinions in high level include maintaining online relationship followed by supporting communication, teaching and learning management, and students' online collaboration, and shaping up students' netiquette.

Based on the research findings, innovative teaching methods including the use of social media for instructional purposes can keep the students engaged and motivated especially by the video on YouTube. That is because through the use of video during lectures, before lectures or at the end of lectures, students are more alert, motivated and focused on the target topic. Moreover, there are recognized connections between visual content, memory knowledge, and students' ability to retain new information. The growing use of social media platforms in teaching and learning is, therefore, a key aspect of successful active learning both inside and outside classroom [16].

Moreover social media has changed the traditional classroom instruction in many ways. Social media has changed how teachers and students communicate, and how students and students communicate. This in turn allows students to enjoy the charm of their state-of-the-art gadgets in their daily life as well as in learning contexts. Instead of relying on contents provided by their teachers, students can access to updated contents, follow current events, and retrieve related information in the forms of texts, pictures, and videos for class reports or projects. Thanks to the amazing function of social media, it helps release the creative and unique work of students to the world. Social media can, therefore, assist students to learn in a meaningful way if social media-based activities are designed carefully and purposefully.

In addition, based on the findings concerning the faculty members' opinions towards the use of social media for instructional purposes, the perceived value of the usefulness of social media for instructional purposes is in highest level. That is to say the faculty members not only use social media privately, they also use it academically. The social media tools today can change the perception of traditional teaching and learning in the classroom. One reason why the faculty members perceived the usefulness of the use of social media for instructional purposes is that social media tools allow users to interact freely and easily in a variety of communication exchanges, and this lead to developments in both identity and self-esteem. Identity can be constructed virtually in these social media spaces by posting, sharing, and creating. In this way these social media platforms serve as handy and friendly teaching aids if the classroom instruction including social media-based activities is designed carefully and purposefully. Moreover, self-esteem building can be the result of virtual communication in the form of Comment, Like and Followers, etc. The term "Net Idol" is, therefore, an example of self-esteem building. However, teachers' presence on social media sites is not for classroom management, but it should be there academically. Students can learn or be inspired by teachers' posts and comments. In terms of 'netiquette', it is also teachers' job to regularly and consistently remind the students of the two-edged sword of social media, and how to behave politely in social media communities.

\section{CONCLUSION}

Social media especially Facebook has become popular all over the world with more than one billions registered accounts [6] due to its amazing functions. Social media can fulfill human's needs for self-actualization to be belonging, for relationship, and for achievement. Moreover, it is user-friendly and free to use. The perceived usefulness and the ease of use of social media enable users to adopt this-stateof-the-art tool as a part of their daily life and people spend long hours using social media to entertain themselves and to satisfy their personal needs. At the same time, more and more faculty members in Higher Education use social media for instructional purposes.

Social media has changed the traditional teaching methodology especially traditional classroom instruction. Today lots of educational institutions provide social media platforms, such as Moodle, and smart classrooms for their faculty members so that social media can satisfy the preferred learning styles of young people who are tech-savvy students, and who long for the informality and relaxing atmosphere of social media. Moreover, the faculty members themselves have designed their classroom instruction with social media-based activities allowing their students to have fun with various social media functions while learning and after learning. Teachers as well as students can now use social media to post, share, and make comments on the related topic. In addition, social media can make studying more collaborative and efficient. Social media can, therefore, help students to create and manage their study, make the best of their study time, find new resources to help them learn and retain knowledge. However, the fast growing Information Communication Technology and social media on its own cannot enable the students to learn. Active instructors with innovative ideas and innovation will still be at the center of the fruitful learning experience.

\section{ACKNOWLEDGMENT}

This is in the acknowledgment of partial funding by Suan Sunandha Rajabhat University's personal development fund for the oral presentation at 7th International Conference on Language, Literature and Linguistics (ICLLL 2017), 9th-11th December 2017, Kyoto, Japan.

\section{REFERENCES}

[1] D. Crystal, English as a Global Language, Cambridge: Cambridge University Press, 1997

[2] Usage of content languages for websites. W3Techs 2016. [Online]. pp. 1-3. Available: https://w3techs.com/technologies/ overview/content_ language/all

[3] J. Melitz. (June 2009). English as a global language: Good for business, bad for literature. Center for economic policy research. CEPR discussion paper. $\quad$ [Online]. $2055 . \quad$ Available: http://www.file://F:IEnglishasthegloballanguage.html 
[4] W. Kunnu, "Teaching speaking skills to adult English language learners through ALM," International Journal of Social Behavioral Education, Economic and Management Engineering, vol. 20, no. 14, pp. 277-287, 2013.

[5] R. O. Gibson. (April 2012). Using social media as a language learning tool. The Guardian. [Online]. pp. 1-4. Available: https://www.theguardian.com/teacher-network/teacher-blog/ 2012/apr/ 10/language-teaching-social-media

[6] D. Chaffey. (February 2017). Global social media research summary 2017. Smart Insight. [Online]. pp. 1-3. Available: http://www.smartinsights.com/social-media-marketing/social-mediastrategy/new-global-social-media-research/

[7] Internet Users Profile, Electronic Transactions Development Agency ETDA Report, Bangkok, Thailand, 2015.

[8] We are social \& hootsuit. New research reveals global social media use increased by 21 percent in 2016. Hootsuit. [Online]. pp. 1-5. Available: https://hootsuite.com/en-gb/newsroom/press-releases/digital-in-2017report

[9] P. Sayer and R. Ban, "Young EFL students' engagement with English outside the classroom," English Language Teaching (ELT) Journal, pp. 321-329, vol. 68, no. 3, 2014.

[10] M. Georgalau, "English \& digital literacies; ICTs in English language teaching," National \& Kapodistrian University of Athens, December 2014.

[11] D. Nations. (March, 2017). What is social media? Explaining the big trend. Lifewire. [Online]. pp. 1-7. Available: https://www.lifewire.com/what-is-social-media-explaining-the-big-trend $-3486616$

[12] A. O. Jonathan and W. Steve, "Social media definition and the governance challenge; an introduction to the special issue," Telecommunication Policy, vol. 39, no. 9, pp. 745-750, 2015.

[13] K. Zourou, "On the attractiveness of social media for language learning; a look at the state of the art," Alsic, vol. 15, no. 1, November 2012.

[14] D. R. Garrison, T. Anderson, and W. Archer, "Critical inquiry in a text-based environment: Computer conferencing in higher education," The Internet and Higher Education, vol. 2, no. 2-3, pp. 87-105, 2000,

[15] D. R. Garrison and N. Vaughan, Blended Learning in Higher Education: Framework, Principles, and Guidelines, San Francisco: John Wiley \& Sons, 2007.

[16] C. Baker, "The impact of instructor immediacy and presence for online student affective learning, cognition and motivation,” Journal of Educators, vol. 7, pp. 1-30, October 2010.

[17] E. Luyegu. (June 2016). Ensuring presence in online learning environments. IGI Global. [Online]. pp 1-5. Available: http://www.igi-global.com/chapter/ensuring-presence-in-online-learningenvironments/140 653

[18] R. O. Gibson. (April 2012). Using social media as a language learning tool. The Guardian. [Online]. pp. 1-10. Available: https://www.theguardian.com/teacher-network/teacher-blog/2012/apr/1 0/language-teaching-social-media

[19] M. D. Roblyer and A. H. Doering, Netiquette: Rules and Behavior on the Internet, New York: Pearson Allyn Bacon Prentice Hall, 2013.

[20] T. Hayton. (2017). Using social media in the classroom. British Council. [Online]. p. 3. Available: https://www. teachingenglish org.uk/article/using-social-media- classroom

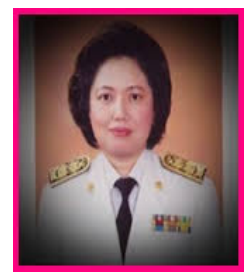

Nithiwadee Kosarussawadee was born in Phitsanulok, Thailand in 1966. She received her bachelor's degree of arts majoring in English, Chulalongkorn University, Bangkok, Thailand, 1987. She received her master's degree of arts in linguistics, Chulalongkorn University, Bangkok, Thailand, 1990. She started her career in teaching English at the Department of Foreign Languages at the Faculty of Humanities and Social Sciences, Pibulsongkram Teacher's College from 1990 to 1995 . The she moved to Suan Sunandha Rajabhat University, Bangkok in 1995 and has been working here up to now.

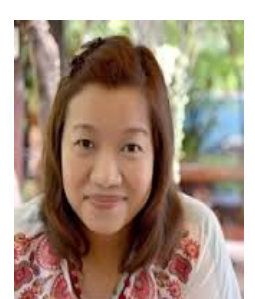

Aungkana Sukwises was born in Bangkok, Thailand in 1976. She received her bachelor's degree of arts majoring in English language and literature, Thammasat University, Bangkok, Thailand, 1996. She received her master's degree of arts in comparative literature, Chulalongkorn University, Bangkok, Thailand, 2001. She started her career in teaching English in English language program, Faculty of Humanities and Social Sciences, Suan Sunandha Rajabhat University, Bangkok, Thailand from 2000 up to now.

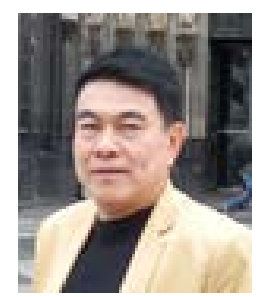

Chaiwat Tantarangsee was born in Ratchaburi province, Thailand in 1955 . He received his bachelor's degree in Education majoring in Teaching English, Chulalongkorn University, Bangkok, Thailand, 1976. He received his master's degree in education in teaching English as a foreign language, Chulalongkorn University, Bangkok, Thailand, 1993 He started his career in teaching English in a secondary school, Ratchaburi, Thailand, in 1997, and had experiences in teaching English in secondary school level for 16 years. From 2002 up to now he was an assistant professor in English language program, Faculty of Humanities and Social Sciences, Suan Sunandha Rajabhat University, Bangkok, Thailand. Now he is a pensioner working part time at Suan Sunandha Rajabhat University. He has been published several articles in international journals. 